\title{
Study of DYS 390 Polymorphism among Khatri Population of Punjab in Comparison to Other Indian and World Population
}

\author{
Badaruddoza $^{1}$, A.J.S. Bhanwer ${ }^{1}$, Rupinder Kaur ${ }^{1}$, R. Singh ${ }^{1}$, Matharoo. K ${ }^{1}$ and R.N.K. Bamezai ${ }^{2}$ \\ 1. Department of Human Genetics, Guru Nanak Dev University, Amritsar 143 005, Punjab, India \\ 2. National Centre of Applied Human Genetics, SLS, JNU, New Delhi, India
}

KEYWORDS Khatri population; Punjab; polymorphism; DYS390 locus

\begin{abstract}
The Y chromosome specific polymorphism (Y-STR and Y-SNPs) can be used to track paternal lineages as well as male specific movements and admixture among humans. The objective of the present work is to study the genetic polymorphism at Y chromosome specific STR locus, DYS390 among Khatri population of Punjab and generate a comparative data with respect to other Indian and world populations. The DNA was isolated from blood samples of Khatri male individuals through organic method and were amplified by PCR using specific primers for DYS390 locus. The PCR products were electrophoresed on polyacrylamide gels and silver staining was done to resolve and observe different alleles. Gel-Pro 3.1 software was used to confirm the allele size. Chi-Square test was applied to test whether differences between the allele frequencies among Khatri, other Indian and world populations were statistically significant. Network Joining (NJ) tree was constructed using Network analysis software. The results showed 7 different alleles ranging from 22 to 28 in Khatri population and revealed a significantly high degree of genetic heterogeneity at this locus. The gene diversity was found to be 0.8363 . The Network Joining tree showed Khatri population as an independent branch alongside Chinese. Therefore, it can be inferred that Khatri population is probably a result of conglomeration of different lineages, like most other North-West Indian population.
\end{abstract}

\section{INTRODUCTION}

Khatri caste is one of the major business communities of Punjab (India). In pre independence era, they were mostly settled in the Western part of undivided Punjab state but subsequently after independence, they migrated to Indian part of Punjab and other North Western states of India like Haryana, Himachal Pradesh, Delhi and Uttar Pradesh. The aim of the present study is to bring the most mobile Khatri population of the state of Punjab on the molecular genetic map of the world through the study of genetic polymorphism at Y-chromosome specific STR locus DYS 390.

The male-specific essentially haploid Ychromosome is one of the smallest human chromosomes with an average size of 60 million base pairs. The non-recombining portion of Ychromosome contains different kinds of polymorphisms with known mutation rates. It is inherited as a single unit or haploid through paternal line of transmission (Vandenberge et al. 1999; Ploski et al. 2002). Recently, there has been a rapid growth in the discovery of new Y-STR

Address for Correspondance: Dr. Badaruddoza, Department of Human Genetics, Guru Nanak Dev University, Amritsar 143005, Punjab, India

E-mail:doza13@yahoo.co.in markers (Kayser et al. 1997; Jobling et al. 1998; Ayub et al. 2000; Bosch et al. 2000; Butler 2003; Jobling and Tyler-Smith 2003; Deng et al. 2004; Shephered et al. 2004) to investigate the population affinities, their origin and subsequent distribution in various parts of globe. The Y-STR loci became also useful markers to identify male lineage in forensic practice.

\section{MATERIALS AND METHODS}

Blood samples of individuals belonging to Khatri population were collected randomly after obtaining informed written consent from the donor and for the DYS390 polymorphism survey, a total of 146 samples were analysed. DNA was extracted from blood samples by organic method (Gill et al. 1987) through phenol/chloroform extraction. The quality and quantity of DNA was checked by agarose gel electrophoresis. The PCR conditions for DYS390 consisted of an initial denaturation at $95^{\circ} \mathrm{C}$ for 2 minutes followed by 30 cycles of denaturation at $94^{\circ} \mathrm{C}$ for 1 minute, primer annealing at $50^{\circ} \mathrm{C}$ for 1 minute and primer extension at $72^{\circ} \mathrm{C}$ for 1 minute. The final extension step was extended to 10 minutes followed by incubation at $4^{\circ} \mathrm{C}$. The primers used for PCR to amplify DYS 390 were as follows:

Forward: 5'-TTATTTTACACATTTTTGGG 
Reverse: 5'TGACAGTAAAATGAACACA TTGC-3'

After PCR amplification, the samples were electrophoresed on non-denaturing $10 \%$ polyacrylamide gel (Maniatis et al. 1989) for $18 \mathrm{hr}$ at constant voltage of $100 \mathrm{~V}$. The gels were then silver stained to visualize various alleles at this locus and photographed.

Gene diversity D was used to measure the informativeness of each locus. Values for each locus were calculated as per Nei (1987):

$\mathrm{D}=1-\sum \mathrm{x}_{\mathrm{i}}^{2}$, where the $\mathrm{x}_{\mathrm{i}}$ is the allele frequency in a population. The measure of genetic similarity $\left(\mathrm{I}_{\mathrm{N}}\right)$ and distance $\left(\mathrm{D}_{\mathrm{N}}\right)$ were also calculated as per Nei and Kumar (2000), $\mathrm{I}_{\mathrm{N}}$

$$
=\sum_{\mathrm{i}=1}^{\mathrm{m}}\left(\mathrm{p}_{\mathrm{ix}} \mathrm{p}_{\mathrm{iy}}\right) / \sqrt{ }\left(\sum_{\mathrm{i}=1}^{\mathrm{m}} \mathrm{p}_{\mathrm{ix}}^{2}\right)\left(\sum_{\mathrm{i}=1}^{\mathrm{m}} \mathrm{p}^{2}{ }_{\text {iy }}\right)
$$

and then transformed this to obtain Nei's Genetic

Distance: $\mathrm{D}_{\mathrm{N}}=-\ln \left(\mathrm{I}_{\mathrm{N}}\right)$.

Where $p_{i x}$ is the frequency of allele $i$ in the population $\mathrm{p}_{\text {iy }}$ is the frequency of allele $\mathrm{i}$ in the population $\mathrm{Y}, \mathrm{m}$ is the number of alleles at the locus and $\ln$ is logarithm to the base e. The Network Joining (NJ) trees were calculated through
PHYLIP3.6 (Phylogeny inference package) and TREVIEW 1.6.6 software.

\section{RESULTSAND DISCUSSION}

Y-chromosome polymorphisms especially YSTRs and Y-SNPs can be used to track paternal lineages as well as male specific movements and admixtures (Butler 2003). From the minisequenencing 7 regional population groups in India and 10 continental population groups from the data published by Gresham et al. (2001), Kayser et al. (2001), Qamar et al. (2002) and Saha et al. (2005) were used for comparison with the present data (Table 1 and 2). A total of seven different alleles from 22 to 28 were observed with a size range of 207-231 bp in Khatri population. The highest allele frequency was found for allele 24 and lowest for allele 22. This shows a significant high degree of genetic polymorphism at this locus. Most of the allele combinations were found to be balanced between the different Indian and world populations. However, the present Khatri population is characterized by a

Table 1: Comparison of Y-STR allele distributions and frequencies for microsatellites DYS390 among Khatri and other reported Indian population (Saha and Bamezai 2000; Saha et al. 2005)

\begin{tabular}{|c|c|c|c|c|c|c|c|c|c|c|}
\hline \multirow[t]{2}{*}{ Populations } & \multicolumn{10}{|c|}{ Allele frequencies } \\
\hline & 20 & 21 & 22 & 23 & 24 & 25 & 26 & 27 & 28 & $\Sigma$ \\
\hline Khatri & 0 & 0 & 0.06 & 0.12 & 0.22 & 0.18 & 0.10 & 0.20 & 0.12 & 1.00 \\
\hline Kashmiri Pandits & 0 & 0.093 & 0.148 & 0.278 & 0.148 & 0.203 & 0.13 & 0 & 0 & 1.00 \\
\hline Kashmiri Muslims & 0.026 & 0.051 & 0.103 & 0.205 & 0.308 & 0.307 & 0 & 0 & 0 & 1.00 \\
\hline Uttar Pradesh (UP) & 0 & 0.026 & 0.053 & 0.237 & 0.158 & 0.158 & 0.263 & 0.105 & 0 & 1.00 \\
\hline West Bengal (WB) & 0 & 0 & 0.111 & 0.333 & 0.222 & 0.223 & 0 & 0.111 & 0 & 1.00 \\
\hline Punjab & 0 & 0 & 0.421 & 0.158 & 0 & 0.263 & 0.105 & 0.053 & 0 & 1.00 \\
\hline Bihar & 0 & 0.026 & 0.154 & 0.205 & 0.179 & 0.179 & 0.205 & 0.052 & 0 & 1.00 \\
\hline South India & 0 & 0 & 0.316 & 0.105 & 0.263 & 0.158 & 0.158 & 0 & 0 & 1.00 \\
\hline
\end{tabular}

Table 2: Comparison of Y-STR allele distributions and frequencies for microsatellite DYS-390 among Khatri and other reported world population (Gresham et al. 2001; Kayser et al. 2001; Qamar et al. 2002).

\begin{tabular}{|c|c|c|c|c|c|c|c|c|c|c|}
\hline \multirow[t]{2}{*}{ Populations } & \multicolumn{10}{|c|}{ Allele frequencies } \\
\hline & 20 & 21 & 22 & 23 & 24 & 25 & 26 & 27 & 28 & $\Sigma$ \\
\hline Khatri & 0 & 0 & 0.06 & 0.12 & 0.22 & 0.18 & 0.10 & 0.20 & 0.12 & 1.00 \\
\hline Pygmies & 0 & 0.323 & 0.065 & 0.29 & 0.065 & 0.257 & 0 & 0 & 0 & 1.00 \\
\hline Chinese & 0 & 0.029 & 0.057 & 0.543 & 0.229 & 0.142 & 0 & 0 & 0 & 1.00 \\
\hline German & 0 & 0 & 0.080 & 0.322 & 0.287 & 0.253 & 0.058 & 0 & 0 & 1.00 \\
\hline Indonesian & 0 & 0.116 & 0.058 & 0.246 & 0.319 & 0.247 & 0.014 & 0 & 0 & 1.00 \\
\hline Inuit Greenland & 0 & 0 & 0.048 & 0.065 & 0.855 & 0.032 & 0 & 0 & 0 & 1.00 \\
\hline Mongolian & 0 & 0 & 0.075 & 0.250 & 0.375 & 0.275 & 0 & 0.025 & 0 & 1.00 \\
\hline Romani Europe & 0 & 0 & 0.753 & 0.118 & 0.112 & 0.017 & 0 & 0 & 0 & 1.00 \\
\hline Pakistani Burusho & 0.011 & 0 & 0.309 & 0.255 & 0.233 & 0.181 & 0.011 & 0 & 0 & 1.00 \\
\hline Pakistani Balti & 0 & 0 & 0.231 & 0.154 & 0.154 & 0.461 & 0 & 0 & 0 & 1.00 \\
\hline Italian & 0 & 0.01 & 0.152 & 0.394 & 0.383 & 0.051 & 0.01 & 0 & 0 & 1.00 \\
\hline
\end{tabular}


more uniform distribution of genotypes and also showed the presence of longest allele 28 which is not found in any other population from India and the world. The lesser common alleles 26 and 27 are present in some world population with low frequency, and are absent in others. It can be seen that four alleles as $22,23,24$ and 25 are forming a cluster in most of the world populations. Thus, the genetic affinity of Khatris with neighbouring sub-continental, European and East Asian population is evident.

To compare the degree of gene diversity between Khatri and other populations, Nei's (1987) method was used. The gene diversity ranges for different categories of populations are given in Table 3. The relatively higher value of gene diversity (0.8363) for DYS 390 STR locus has been found in Khatri population and it is lowest for Chinese group (0.628171). This indicates that Khatri is a large population and has high genetic admixture with external gene flow. This is a characteristic feature of mainland population. Low gene diversity indicates that it has little genetic admixture and is a characteristic feature of tribal population (Kumar and Reddy 2003; Reddy et al. 2005).

It has also been found that the present Khatri population exhibits more similarity to some populations of UP (India) and Burusho (Pakistan). The allele 28 for DYS 390 locus is not found in any other reported ethnic groups, thus the Khatri population of Punjab represents a distinct ethnic group in the region.
Based on the allele frequency data, Nei and Kumar's (2000) standard genetic distances were computed and processed in PHYLIP 3.6 software to get an 'outfile'. The given outfile was opened in TREEVIEW to get the Neighbour Joining Tree (Fig. 1). It shows Khatris in an independent branch alongside Chinese. This is followed by a group of pygmies and south Indian population.

A perusal of above given facts makes it possible to conclude, that Khatri population is most probably a result of conglomeration of different lineages like most other North-West

Table 3: Comparison of gene diversity values among Khatri and other reported Indian and world populations

\begin{tabular}{lr}
\hline Population & Gene Diversity Value \\
\hline Khatri & 0.836800 \\
Kashmiri Muslim & 0.754361 \\
Kashmiri Pandits & 0.811783 \\
Uttar Pradesh (UP) & 0.780224 \\
West Bengal (WB) & 0.765901 \\
Punjab & 0.714792 \\
Bihar & 0.824875 \\
South India & 0.770022 \\
Pygmies & 0.736557 \\
Chinese & 0.628171 \\
German & 0.740289 \\
Indonesian & 0.760191 \\
Mongolian & 0.715000 \\
Italian & 0.671403 \\
Pakistani Balti & 0.685763 \\
Pakistani Burusho & 0.751735 \\
Inuit Greeland & 0.261422 \\
Romani Europe & 0.406234 \\
\hline
\end{tabular}

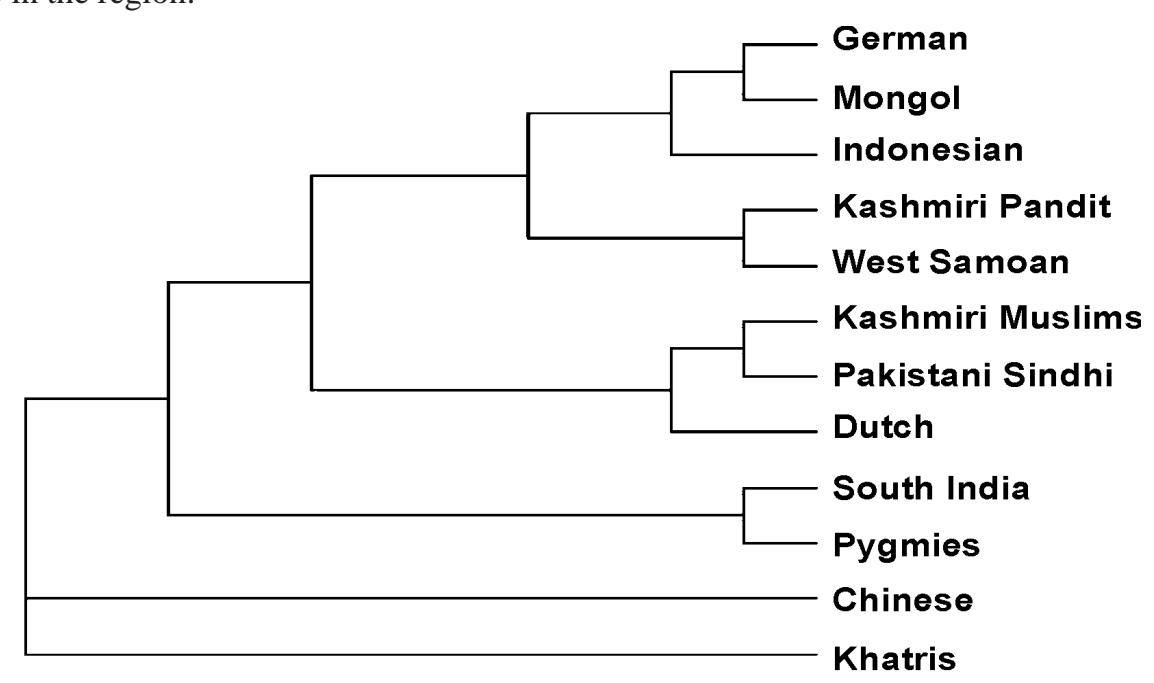

Fig. 1. Unrooted NJ tree showing relation between Khatris and different world population based on DYS390-STR marker 
Indian populations (Majumder 2001; Saha et al. 2003; Saha and Bamezai 2000). The results of this study can only be reinforced by further study with larger sample size as well as more DNA markers.

\section{REFERENCES}

Ayub Q, Mohyuddin A, Qamar R, Mazhar K, Zerjal T, Mehdi SQ, Tyler-Smith C 2000. Identification and characteristization of novel Y-chromosomal microsatellites from sequence database information. Nucleic Acids Res, 28: e8.

Bosch E, Calafell F, Perez-Lezaun A, Comas D, Izaabel H, Akhayat O, Sefiani A, Hariti G, Dugoujon J M, Bertranpetit J 2000. Y chromosome STR haplotypes in four populations from North-West Africa. Int J Legal Med, 114: 36-40.

Butler JM 2003. Recent developments in Y-Short Tandem Repeat and Y-Single Nucleotide Polymorphism Analysis. Forensic Sci Rev, 15: $92-$ 111 .

Deng Z H, Wu GG, Zhang X 2004. Genetic polymorphisms of $6 \mathrm{Y}$ chromosome specific STR loci in the Southern Chinese Han population and its application in forensic sciences. Yi Chuan, 26: 446450 .

Gill P, Lygo JE, Fowler SJ 1987. An evaluation of DNA fingerprinting for forensic purposes. Electrophoresis, 8: $38-44$.

Gresham D, Morar B, Underhill PA, Passarimo G, Lin AA, Wise C, Angelicheva D, Calafill F, Oefner PJ, Shen P, Tournev I, Kucinskas V, Perez- Lezaum A, Marushiakova E, Popov V, Kalaydjieva L. 2001. Origins and divergence of the Roma (Gypsies). Am J Hum Genet, 69: 1314-1331.

Jobling MA, Bouzekri N, Taylor PG 1998. Hypervariable digital DNA codes for human paternal lineages: MVR PCR at the Y-specific minisatellite, MSY1 (DYF155S1). Hum Mol Gene, 7: 643-653.

Jobling MA, Tyler-Smith C 2003. The Human YChromosome: An Evolutionary Marker Comes of Age. Nature, 4: 599-612.

Kayser M, Caglia A, Corach D, Fretwell N, Gehrig C, Graziosi G, Heidorn F, Herrnann S, Herzog B, Hiding M, Honda K, Jobling M, Krawczak M, Leim K, Meuser S, Meyer E, Oesterreich W, Pandya A, Parson W, Penacino G, Perez-Lezaun A, Piccinini A, Prinz M, Schmitt C, Roewer L 1997. Evaluation of Y-chromosomal STRs : A multicenter study. Int J Legal Med, 110: 125-133.

Kayser M, Krawczak M, Excoffier L, Dieltjes P, Corach D, Pascali V, Gehrig C, Bernini LF, Jespersen T, Bakker E, Roewer L, Knijff P 2001. An Extensive
Analysis of Y-Chromosomal Minisatellite Haplotypes in Globally Dispersed Human Populations. Am J Hum Genet, 68: 990-1018.

Kumar V, Reddy BM 2003. Status Of Austro-Asiatic Groups In The Peopling Of India: An Exploratory Study Based On The Available Prehistoric, Linguistic And Biological Evidences. J Biosci, 28: 507-522.

Majumder PP 2001. Ethnic Populations of India as seen from an Evolutionary Perspective. J Biosci, 26: 533-543.

Maniatis T, Sambrook J, Fristsch EF 1989 Molecular Cloning: A Laboratory Manual. Cold Spring Harbor, NY: Cold Spring Harbor University Press.

Nei M 1987. Molecular Evolutionary Genetics. New York Chichester: Columbia University Press. pp. 177-179.

Nei M, Kumar S 2000. Molecular Evolution and Phylogenetics. New York: Oxford University Press.

Ploski R, Wozniak M, Pawlowski R, Monies DM, Branicki W, Kupiec T, Kloosterman A, Dobosz T, Bosch E, Nowak M, Lessig R, Jobling MA, Roewer L, Kayser M 2002. Homogeneity and Distinctiveness of Polish Paternal Lineages Revealed by YChromosome Microsatellite Haplotype anlaysis. Hum Genet, 110: 592-600.

Qamar R, Ayub Q, Mohyuddin A, Helgason A, Mazhar K, Mansoor A, Zerjal T, Tyler-Smith C, Mehdi SQ 2002. Y-Chromosomal DNA Variation In Pakistan. Am J Hum Genet, 70: 1107-1124.

Reddy BM, Naidu VM, Madahvi VK, Thangaraj K, Kumar V, Langstieh BT, Venkatramana P, Reddy AG, Singh L 2005. Microsatellite Diversity in Andhra Pradesh, India: Genetic Stratification versus Social Stratification. Hum Biol, 77: 803-823.

Saha A, Bamezai R 2000. Detection of Genetic Variation in Indian Population groups using a Novel Minisatellite Probe and Finding Relationships through Trees Construction. J Hum Genet, 45: 207211.

Saha A, Udhayasuriyan PT, Bhat KV, Bamezai R 2003. Analysis of Indian Populations Based on Y-STR's Reveals Existence of Male Gene Flow across Different Language Groups. DNA Cell Biol, 22: 707-719.

Saha A, Sharma S, Bhat A, Pandit A and Bamezai R 2005. Genetic Affinity Among Five Different Population Groups In India Reflecting a Y-Chromosome Gene Flow. J Hum Genet, 50: 49-51.

Shepherd C, Harbison S, Vintiner J 2004. Y- STR Haplotypes Data for New Zealand Population Groups Using the Y-Plex 6 Kit. Forensic Sci Int, 145: $69-72$.

Vandenberg N, Van Oorschot RAH, Tyler-Smith C, Mitchell RJ 1999. Y-Chromosome-Specific Microsatellite Variation in Australian Aboriginals. Hum Biol, 71: 915-931. 